\title{
Biosimilar Epoetin Zeta in Oncology and Haematology: Development and Experience following 6 Years of Use
}

\author{
Mauricette Michallet ${ }^{\mathrm{a}}$ Christoph Losem ${ }^{\mathrm{b}}$ \\ ${ }^{a}$ Centre Hospitalo-Universitaire de Lyon Sud, Pierre Bénite, France; ${ }^{b}$ Praxis für Onkologie und Hämatologie, \\ Neuss, Germany
}

\section{Key Words}

Biosimilars - Chemotherapy-induced anaemia - Epoetin alfa . Epoetin zeta · Erythropoietin · Haematology · Oncology

\begin{abstract}
Chemotherapy-induced anaemia is frequent in cancer patients, with severity depending on the extent of the disease and intensity of treatment. Clinical guidelines recommend erythropoietin therapy to treat or prevent anaemia in some oncology/haematology patients being treated with chemotherapy. The patent expiry of the first-generation erythropoietins has led to the development of biosimilar products, i.e. therapeutic proteins exhibiting comparable quality, safety and efficacy to an existing reference biological medicine, the patent of which has expired. This review summarises the available data set supporting the use of one such biosimilar product, epoetin zeta (Retacrit ${ }^{T M}$ ) in oncology/haematology. The body of evidence supporting the use of epoetin zeta continues to grow, with post-marketing clinical studies underway to evaluate its longer-term clinical efficacy and safety. Biosimilar medicines have the potential to offer cost savings to health care providers, with the assurance of ongoing risk management programmes to ensure patient safety.
\end{abstract}

(c) 2015 The Author(s)

Published by S. Karger AG, Basel

\section{KARGER}

E-Mail karger@karger.com www.karger.com/aha

(C) 2015 The Author(s)

Published by S. Karger AG, Basel 0001-5792/15/1351-0044\$39.50/0

This article is licensed under the Creative Commons AttributionNonCommercial-NoDerivatives 4.0 International License (CC BYNC-ND) (http://www.karger.com/Services/OpenAccessLicense). Usage and distribution for commercial purposes as well as any distribution of modified material requires written permission.

\section{Introduction}

Anaemia is frequent in cancer patients, with a recent European cancer survey revealing that $67 \%$ of cancer patients had haemoglobin $(\mathrm{Hb})$ levels of $<10 \mathrm{~g} / \mathrm{dl}$ during a 6 -month period [1]. Furthermore, the incidence of anaemia increases with chemotherapy and with the severity of anaemia depending on the extent of disease and intensity of treatment [2]. The highest rates of chemotherapy-induced anaemia (CIA) are observed in patients with lung and ovarian cancer $[1,2]$. CIA can result in fatigue and impaired quality of life (QoL) [3], and the level of anaemia has been shown to correlate with QoL in cancer patients [4]. CIA is also independently associated with reduced survival rates in patients with solid tumours, lymphoma or myeloma [5]. Clinical guidelines recommend erythropoietin (EPO) therapy to treat or prevent anaemia in oncology/haematology [6,7]. Evidence from clinical research shows that EPO improves Hb levels and reduces the risk of transfusion. The best evidence exists to support the use of EPO to correct CIA if Hb levels are $\leq 10 \mathrm{~g} / \mathrm{dl}$ [6]. Erythropoiesis-stimulating agents (ESAs) are not recommended for prophylaxis of anaemia in patients with normal $\mathrm{Hb}$ values prior to undergoing chemotherapy and/or radiotherapy [6]. It is important to consider the

Prof. Mauricette Michallet

Service d'Hématologie, Centre Hospitalo-Universitaire de Lyon Sud 165 Chemin du Grand Revoyet

FR-69495 Pierre Bénite Cedex 03 (France)

E-Mail mauricette.michallet@chu-lyon.fr 
Fig. 1. The clinical development of biosim-

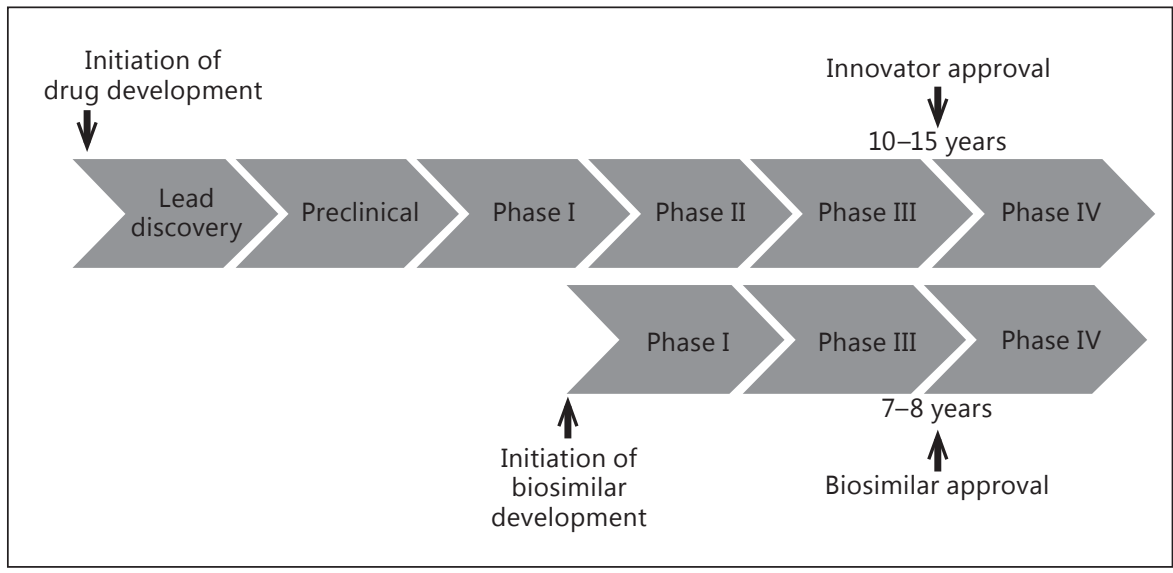

target $\mathrm{Hb}$ levels that ESA therapy is designed to achieve; guidelines suggest a sustained $\mathrm{Hb}$ level of $12 \mathrm{~g} / \mathrm{dl}$ should be the target of treatment with ESAs [6]. A number of ESAs have become available since the first epoetins were approved (in the USA: Epogen ${ }^{\circledR}$; Amgen, Thousand Oaks, Calif., USA; outside the USA: Eprex ${ }^{\circledR}$; Janssen Cilag, Zug, Switzerland). ESA therapy has now evolved, with longer-acting second-generation (darbepoetin alfa, Aranesp ${ }^{\circledR}$; Amgen) and third-generation (pegylated epoetin beta, Mircera ${ }^{\circledR}$; Roche, Basel, Switzerland) ESAs also available. The patent expiry of the first-generation EPOs has led to the development of biosimilar products.

\section{What Are Biosimilars?}

Biosimilars are therapeutic proteins exhibiting comparable quality, safety and efficacy to an existing reference biological medicine, the patent of which has expired [8]. The European Union (EU) has pioneered biosimilar legislation [9]. The resultant guidelines, now also adopted by the World Health Organization [10], are significantly different to those governing generic medicines, due to the larger size and complexity of the proteins used, as well as the issues of comparability when using different cell lines. Biosimilars have brought about cost benefits and competition to the marketplace $[11,12]$; however, the primary concerns of the treating physician/oncologist/haematologist are the efficacy, safety and quality of the treatment. In the EU and other highly regulated markets, strict regulatory requirements ensure the efficacy, safety and quality of biosimilar products. Quality studies have demonstrated that biosimilars have comparable quality to their reference products [13]. In this review, we discuss epoetin zeta (Retacrit ${ }^{\mathrm{TM}}$; Hospira UK Ltd., Leamington Spa, UK) and epoetin alfa (Eprex ${ }^{\circledR}$; Janssen Cilag) to highlight the clinical and regulatory issues involved with the development of biosimilar ESAs.

\section{Clinical Development}

Drug development is a complex, time-consuming, costly and highly regulated process. It takes at least 10 years to develop a new medicine and the average cost of research is estimated to be approximately USD 2.6 billion; this figure takes into account the high rate of attrition [14]. Biosimilars have an abbreviated development pathway, also requiring significant investment, technical capability and clinical trial expertise. Although biosimilars do not require the same development costs, EU guidelines require the demonstration of biosimilarity to the reference product in terms of structural and functional characteristics, and clinical confirmation consisting of pharmacokinetic (PK) equivalence (phase I trials) and therapeutic equivalence in a sensitive patient population (phase III trials; see fig. 1). The costs of biosimilars are therefore typically lower than their reference products but significantly higher than generic medicines.

\section{The Process of Manufacturing}

Biological medicines are recombinant proteins expressed in cell lines and are affected by post-translational modifications such as glycosylation. Following production, these proteins must be purified from other cellular components [8]. Due to the inherent complexity of a bio- 
Table 1. Summary of EMA requirements for approval of biosimilar ESAs [20]

\begin{tabular}{ll}
\hline Stage of comparability & Requirement \\
\hline Preclinical studies & $\begin{array}{l}\text { Comparative non-clinical studies } \\
\text { 28-day toxicology }\end{array}$ \\
\hline Human PK and PD studies & $\begin{array}{l}\text { Single-dose SC and IV in healthy volunteers } \\
\text { Include PD evaluation (reticulocytes) in PK studies }\end{array}$ \\
\hline Efficacy studies & Two randomised, double-blind studies in nephrology \\
& Both routes of administration (SC and IV) \\
& Dose and Hb levels to be collected \\
\hline Extrapolation & $\begin{array}{l}\text { Yes - equivalence in renal anaemia may allow extension to other indications if } \\
\text { justified by applicant }\end{array}$ \\
\hline Safety & $\begin{array}{l}\text { Safety from efficacy studies is adequate for approval } \\
\text { 12-month, comparative immunogenicity data }\end{array}$ \\
\hline Pre-approval commitments & $\begin{array}{l}\text { PRCA to be addressed in cohort of patients from all indications (i.e. including } \\
\text { extrapolated indications) }\end{array}$ \\
\hline
\end{tabular}

PRCA = Pure red cell aplasia. Adapted from Mellstedt et al. [20].

logical molecule such as epoetin alfa, any modifications in the manufacturing process (such as the use of different cell lines or purification methods) lead to differences in the final product [15]. This is true for all biologicals, including biosimilars.

The structural and functional characterisation that is required by the regulator occurs after any manufacturing changes for reference biologicals to compare a pre- to a post-change product. This is the basis for the extensive comparability exercise fundamental to establishing biosimilarity. As such, the EMA guidelines set out general principles, including preclinical activities to clinical development and the manufacture of biosimilars $[9,16]$. Furthermore, guidance exists for the development of specific biosimilar products, including ESAs [17], G-CSFs (granulocyte-colony stimulating factors) [18] and somatropins [19] - a summary of the preclinical and clinical studies required for EMA approval of biosimilar ESAs as well as the post-approval commitments are shown in table $1[20]$.

\section{Confirming Biosimilarity: Phase I Studies}

PK and PD (pharmacodynamic) studies are an important step in establishing bioequivalence. The PK properties of epoetin zeta compared to epoetin alfa after a single intravenous (IV) injection was studied in 24 healthy vol- unteers during a two-period, single-centre crossover trial [21]. The PK parameters for epoetin zeta and epoetin alfa, as measured by immunoassay of blood samples up to $72 \mathrm{~h}$ post-dose, fulfilled the bioequivalence limits, as required by EU guidelines.

A second, three-period crossover trial examined the bioavailability of epoetin zeta and PK properties compared to epoetin alfa following a single subcutaneous (SC) or IV injection in 48 healthy volunteers for up to $72 \mathrm{~h}$ post-dose [22]. The bioavailability of epoetin zeta was measured as $24 \%$ and the PK properties were once again comparable to those for epoetin alfa.

\section{Establishing Biosimilarity: Phase III Trials}

\section{Clinical Data for Epoetin Zeta in Renal Anaemia}

EU guidelines for the development of biosimilar ESAs require comparability to the reference product to be conducted in the renal anaemia setting [17] as sensitivity to the effects of epoetin is higher in EPO-deficient than nonEPO-deficient conditions and is also dependent on the responsiveness of the bone marrow. Following promising $\mathrm{PK}$ and PD results, several phase III trials were undertaken in the renal population to demonstrate similarity to the reference product.

The first of these trials involved 609 haemodialysis patients with chronic kidney disease and anaemia $(\mathrm{Hb}<9 \mathrm{~g} /$ 
dl) randomised to receive IV epoetin alfa or IV epoetin zeta between 1 and 3 times a week for 24 weeks (covering the 'correction phase' of anaemia treatment). In this randomised, double-blind, multinational trial, the mean $\mathrm{Hb}$ concentration and epoetin dose over the last 4 weeks were statistically equivalent between the groups, indicating that epoetin zeta was therapeutically equivalent to epoetin alfa in the correction of Hb levels [23].

A second trial compared epoetin zeta to epoetin alfa in the maintenance phase of treatment (after patients had achieved their target $\mathrm{Hb}$ with a steady dose of epoetin) [24]. This was a randomised, double-blind, crossover, multicentre study in which patients on haemodialysis initially underwent an open, 18-week run-in period on epoetin alfa to achieve the target $\mathrm{Hb}$. A total of 313 patients were randomised to receive either IV epoetin alfa or IV epoetin zeta 1-3 times a week. After a 12-week treatment period, patients were then crossed over to the alternative treatment, at the same dose, for a further 12-week period. The mean Hb levels, weekly epoetin doses and AE profiles were similar throughout the trial duration, supporting the therapeutic equivalence of epoetin zeta to epoetin alfa in the maintenance phase of treatment.

A third randomised, observer-blinded phase III trial investigated the therapeutic equivalence between epoetin alfa and epoetin zeta in the maintenance phase when administered SC one to three times a week to patients on haemodialysis [25]. Following an open-label period of 12-16 weeks on epoetin zeta, a total of 462 patients were randomised to receive either SC epoetin alfa or SC epoetin zeta for 28 weeks. The primary end points were the mean $\mathrm{Hb}$ level and epoetin dose over the last 4 weeks of treatment. Both the dosage and $\mathrm{Hb}$ were within predefined equivalence ranges over the last 4 weeks of treatment, indicating the therapeutic equivalence of SC epoetin zeta and epoetin alfa [25].

The longer-term tolerability of epoetin zeta was investigated in an open-label extension of the correction and maintenance studies $[23,24]$. In this study, patients received IV epoetin zeta 1-3 times per week for 56 (overall patient group, $\mathrm{n}=745$ ) or 108 weeks (Bulgarian subgroup, $n=164)$. Epoetin zeta effectively maintained target $\mathrm{Hb}$ levels for up to 108 weeks with a constant or stable dose (1-3 times per week), therefore indicating that epoetin zeta has good overall long-term tolerability in patients with anaemia and end-stage renal failure on chronic haemodialysis [26]. In these studies epoetin zeta and epoetin alfa had similar and manageable safety profiles and no patients developed anti-EPO antibodies. Furthermore, two post-authorisation safety cohort observation

Biosimilar Epoetin Zeta: 6 Years'

Experience in Haematology and Oncology
(PASCO) studies have been initiated for epoetin zeta to confirm the long-term tolerability profile of epoetin zeta in renal anaemia. PASCO I, a study of 1,500 patients receiving IV epoetin zeta for the treatment of renal anaemia, has recently been completed with the results anticipated in 2015. An additional 3-year post-marketing surveillance study is currently underway (PASCO II); it aims to observe the safety of SC epoetin zeta in 6,700 patients with renal anaemia treated for 3 years to achieve a followup of 20,000 patient-years, the results of which are anticipated in 2018.

\section{Clinical Data for Epoetin Zeta in CIA}

The efficacy of epoetin zeta has also been demonstrated in CIA. In a phase III, open-label, multicentre international trial a total of 216 patients receiving chemotherapy in association with solid or non-myeloid haematological malignancies and at risk of transfusion were assessed over two treatment periods [27]. The first was a 12 -week treatment period in which patients received an anticipated 8 weeks of chemotherapy treatment, and epoetin zeta was started before (in week 0 ) or at the latest together with the new cycle of chemotherapy. The second treatment period included patients undergoing over 12 weeks of epoetin treatment, up to a possible 36 weeks. All patients continued to receive epoetin zeta until 1 month after their last chemotherapy dose. Therefore, treatment periods varied based on the duration of chemotherapy. Epoetin zeta therapy led to an average $\mathrm{Hb}$ increase of $1.8 \mathrm{~g} / \mathrm{dl}( \pm 2.04)$ and $2.3 \mathrm{~g} / \mathrm{dl}( \pm 1.75)$ in the first 12 weeks of treatment. In total, $176 / 216$ patients $(81.5 \%)$ achieved an $\mathrm{Hb}$ response (defined as an $\mathrm{Hb}$ increase of $\geq 1 \mathrm{~g} / \mathrm{dl}$ or a reticulocyte count increase of $\geq 40,000$ cells/ $\mu$ from baseline) [27], and the treatment was well tolerated. Among all tolerability response assessments, $605 / 719(84.1 \%)$ and $602 / 719(83.7 \%)$ were rated as excellent by the investigators and patients, respectively. In the first 12 weeks of epoetin zeta treatment, 9/216 patients (4.2\%; 95\% CI 1.9-7.8\%) experienced a clinically significant thrombotic event. Across both treatment periods, $11 / 216$ patients $(5.1 \%$; $95 \%$ CI $2.6-8.9 \%)$ experienced a clinically significant thrombotic event. The mean epoetin dose varied across the duration of treatment. The initial mean \pm SD weekly epoetin dose in week 1 among the intent-to-treat population was $502.1 \pm 150.1 \mathrm{IU} / \mathrm{kg}$, which decreased to $449.8 \pm 74.3(444.0 \pm 65.8) \mathrm{IU} / \mathrm{kg}$ in week 3 and increased to $572.9 \pm 252.6 \mathrm{IU} / \mathrm{kg}$ in week 6 , followed by an overall decline to $548.8 \pm 269.4 \mathrm{IU} / \mathrm{kg}$ in 

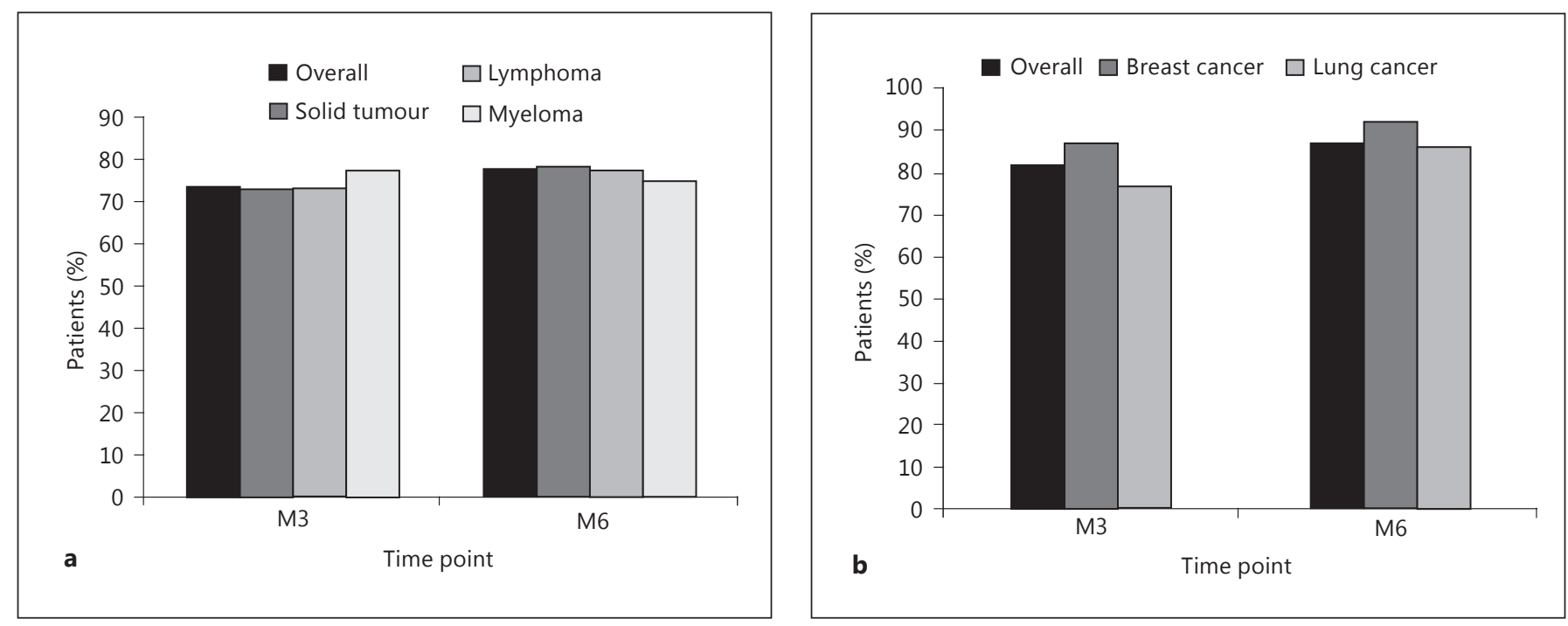

Fig. 2. Treatment response stratified by cancer type (a) and in patients with breast and lung cancer (b) compared to the overall ORHEO study population. Originally published in Michallet et al. [29].

week 11. Continuous improvement in QoL was observed throughout both treatment periods [27]. A phase III clinical trial of epoetin alfa in CIA [22] reported $72.7 \%$ of patients achieving an $\mathrm{Hb}$ increase of $\geq 2 \mathrm{~g} / \mathrm{dl}$, but the patients also received oral iron supplementation and a higher mean epoetin dose (40,000 IU/week) compared to the study carried out by Tzekova et al. [27] (30,000 IU/ week). The mean $\mathrm{Hb}$ response reported in their study is also similar to that reported for epoetin alfa in CIA associated with multiple myeloma [28].

\section{Pharmacovigilance}

Pharmacovigilance is an important requirement for all pharmaceutical products, including biosimilars. EU guidelines for the development of biosimilar epoetins recommend post-marketing surveillance as part of an ongoing benefit-risk assessment [17]. Typically, the risk management plan for a biosimilar is the same as or more extensive than that of the reference biological. Two postmarketing studies have been conducted by Hospira to date to look specifically at the management of anaemia secondary to chemotherapy.

The first ORHEO (biosimilars in the management of anaemia secondary to chemotherapy in haematology and oncology) study was an observational, longitudinal, multicentre study performed in France [29]. The subjects were over 18 years of age, eligible for treatment with an epoetin alfa biosimilar and presenting with CIA (irrespective of the chemotherapy cycle) associated with solid tumours, lymphomas or myelomas. A total of 2,333 patients were included in the study (attending a clinic at least once) from 235 centres. A patient was described as a 'responder' to treatment with an epoetin biosimilar if $\mathrm{Hb}$ levels were at least equal to $10 \mathrm{~g} / \mathrm{dl}$, if there had been an increase in $\mathrm{Hb}$ levels of at least $1 \mathrm{~g} / \mathrm{dl}$ since the inclusion visit, or if the $\mathrm{Hb}$ level reached the target level set by the physician on day 0 , without any blood transfusions in the 3 weeks prior to measurement. At baseline, $57.9 \%$ of the patients had grade 1 anaemia $(9.5-11 \mathrm{~g} / \mathrm{dl})$ and $35.6 \%$ had grade 2 anaemia $(8-9.5 \mathrm{~g} / \mathrm{dl})$. Almost all $(99.9 \%)$ of the patients received the biosimilar epoetin zeta (Retacrit ${ }^{\mathrm{TM}}$; Hospira), with the remainder $(3 / 2,333)$ receiving an alternative biosimilar (epoetin alfa, Binocrit ${ }^{\circledR}$; Sandoz, Holzkirchen, Germany). After 3 months, 81.6\% (95\% CI 79.91-83.26) of the patients had responded to treatment across all disease categories compared to $86.5 \%$ at 6 months (95\% CI $84.80-88.10$ ). The proportions of responders for patients with haematological malignancies (lymphoma and myeloma) and solid tumours were similar (fig. 2a). The treatment response for two of the most commonly reported solid tumours is also shown in figure 2 b. Overall, treatment was well tolerated; $17.1 \%$ of all patients experienced at least one clinically significant adverse event (bleeding, infection, local intolerability at the 
injection site or thromboembolic events). The rate of thromboembolic events was 2.4 and $1.5 \%$ at 3 and 6 months, respectively. During the course of the study, $12 \%$ of the patients were treated with an antithrombotic agent. A rise in blood pressure was reported in $1.3 \%$ of patients at 3 months. The same rate was reported at 6 months. The efficacy and tolerability results of this observational study were similar to those reported in the previous phase III open-label study for epoetin zeta in CIA [27].

A second ORHEO study (NCT01626547) is currently underway in Germany on the use of epoetin zeta only in patients with CIA in association with solid tumours, lymphoma and myeloma. An estimated 300 patients were recruited and observed over a 6-month treatment period (the total study duration was 14 months) [30].

In addition to the two mentioned ORHEO studies, a prospective study testing a minimum of 12 weeks of treatment with epoetin zeta in patients with low-risk myelodysplastic syndrome is ongoing in France in 15 centres (RCB 2012-A01395-38). The main objectives of the study are to individualise the biological predictive factors of response to ESA therapy and to evaluate the efficacy and safety of the use of this treatment in patients with low-risk myelodysplastic syndrome. An additional study of epoetin zeta is also being conducted in adult patients with $\mathrm{Hb}$ levels $\leq 11 \mathrm{~g} / \mathrm{dl}$ induced after allogeneic haematopoietic stem cell transplantation (HSCT) for haematological malignancies after myeloablative or non-myeloablative conditioning regimens. This study follows a previous case control study that demonstrated the positive impact of ESA therapy after allogeneic HSCT on Hb recovery and QoL, as well as a significant reduction in the number of red blood cell transfusions with no effect on survival [31]. The current study is a prospective trial with 60 patients following allogeneic HSCT using biosimilar epoetin zeta to confirm the results observed in the earlier study with EPO alfa.

Between December 18, 2007, and November 30, 2013, the total estimated population exposure (in the oncology and nephrology indication), based on post-marketing sales, was 54,554,947 patient-days (World Health Organization daily defined dose of $1,000 \mathrm{IU}$ ) with over $35,000,000$ patient-days' experience in the oncology indication. To date, the observed post-marketing safety experience with epoetin zeta is consistent with the known profile of epoetin alfa (data on file, Hospira). No cases of pure red cell aplasia have been reported with the use of epoetin zeta during this time.

Biosimilar Epoetin Zeta: 6 Years'

Experience in Haematology and Oncology

\section{Biosimilars in Clinical Practice: Considerations for the Oncologist/Haematologist}

Biosimilar medicines offer additional prescribing options and have the potential to increase access to important therapies; however, it is important for health care professionals to understand the nuances of these agents in comparison to generic medicines. This is particularly important in oncology and haematology as products are given to immunosuppressed patients (who are at higher risk of complications) and to healthy stem cell donors (who derive no therapeutic benefit), thereby requiring the prescribing physician to have a more comprehensive knowledge of biosimilars [32].

\section{Extrapolation}

If clinical similarity for biosimilars is proven for one indication, the EMA has endorsed the concept of data extrapolation based on the scientific justification (non-clinical and clinical) to allow for approval in other indications not clinically studied on a case-by-case basis $[8,9]$. Based on the totality of the evidence submitted, the EMA approved epoetin zeta for use in the following: (1) the treatment of anaemia associated with chronic renal failure in adult and paediatric patients on haemodialysis; (2) adult patients on peritoneal dialysis; (3) severe anaemia of renal origin accompanied by clinical symptoms in adult patients with renal insufficiency not yet undergoing dialysis; (4) anaemia and reduction of transfusion requirements in adult patients receiving chemotherapy for solid tumours, malignant lymphoma or multiple myeloma, and at risk of transfusion, and (5) to increase the yield of autologous blood from patients in a predonation programme among patients with moderate anaemia if blood-saving procedures are not available or are insufficient when the scheduled major elective surgery requires a large volume of blood.

\section{Labelling and Naming of Biosimilar Products}

The labelling and naming of biosimilar products has been under discussion to avoid confusion in prescribing biological medicines and to ensure traceability. This is particularly noteworthy as differentiating one biopharmaceutical from another can be complicated by the fact that some biosimilars have been given the same international non-proprietary name (INN). For example, Eprex ${ }^{\circledR}$

Acta Haematol 2016;135:44-52 
(Epoetin alfa; Janssen Cilag) has been available in Europe for several years. Retacrit ${ }^{\mathrm{TM}}$ (Hospira UK Ltd., Leamington Spa, UK), Binocrit (Sandoz), also marketed as Epoetin Alfa Hexal (Hexal Biotech Forschungs GmbH, Holzkirchen, Germany) and Abseamed (Medice Arzneimittel Pütter GMBH \& Co., Iserlohn, Germany) are biosimilar to Eprex and are all indicated for CIA and renal anaemia. However, Retacrit ${ }^{\mathrm{TM}}$ has a different INN to Eprex (epoetin zeta vs. epoetin alfa), whilst the other biosimilar ESAs mentioned have the same INN (epoetin alfa). Therefore, different biopharmaceutical products can only be identified by their brand names and it is recommended to prescribe biopharmaceuticals by brand name in order to avoid confusion and ensure traceability. Since late 2008, more than $99 \%$ of the post-market reports received by Hospira regarding Retacrit ${ }^{\mathrm{TM}}$ were successfully identified as Hospira's product. Less than $1 \%$ could not be attributed to any brand (data on file, Hospira).

\section{Substitution}

The policy for biosimilar substitution (i.e. the replacement of a reference biological with a biosimilar by a pharmacist) varies by country. However, it is commonplace in medical practice to use the INN as a means of identifying chemical drugs that are identical to one another, as is the case with generic medicines, which could result in automatic substitution. This highlights the importance of clearly identifying the precise agent by using the brand name. Recognising this problem, several European countries have taken steps to limit the automatic substitution of such products $[32,33]$. It is also recommended that substitution should only occur following the instruction of a qualified health care professional [34]. Recent European Organisation for Research and Treatment of Cancer (EORTC) guidelines for the use of G-CSFs emphasise the importance of traceability and advocate against uncontrolled substitution [35]. Traceability helps to ensure the accuracy of post-marketing surveillance.

\section{Switching}

Switching products for efficacy, tolerability or economic reasons should be distinguished from automatic substitution at the pharmacy level. Switching medications is common in the long-term treatment of chronic conditions. The ability to switch epoetin products is less of a concern in CIA compared to renal anaemia; however, studies demonstrating the safety of switching are relevant in further demonstrating the therapeutic equivalence of biosimilar medicines. A recent study suggests that switching is not associated with a change in outcomes [36].

\section{Conclusions}

This review summarises the available data set supporting the use of epoetin zeta in oncology/haematology. The body of evidence supporting the use of epoetin zeta continues to grow. Post-marketing and clinical studies demonstrate clinical efficacy and safety in the oncology and nephrology indications. European exposure data indicate a growing patient population exposed to epoetin zeta (both in the oncology and nephrology indications) without any unexpected adverse events or instances of pure red cell aplasia. Evaluation of the benefit-risk profile of epoetin zeta will continue through additional planned studies and ongoing surveillance throughout its life cycle. These planned studies, in combination with those ongoing in renal anaemia, and investigator-initiated studies comparing both the safety of switching between different epoetin products [36] and the quality of biosimilars compared to reference products [13], further support the use of biosimilar epoetins in both renal anaemia and CIA. Biosimilar medicines have the potential to offer cost savings to health care providers [8], with the assurance of ongoing risk management programmes and benefit-risk evaluation as mandated by the EU [16].

\section{Acknowledgements}

The preparation of this manuscript was supported by Hospira UK Ltd. All authors take full responsibility for the content of the article. The authors would like to thank Andrew Buckley, an employee of Hospira Ltd at the time of preparation of the manuscript, for his critical review of the manuscript. The authors would like to thank Dr. Marion James and Dr. Nason Maani Hessari of apothecom scopemedical ltd (supported by Hospira) for assistance in preparing the manuscript.

\section{Disclosure Statement}

M.M. declares research support from Novartis, Pfizer, Astellas, MSD and Genzyme, has participated on an advisory panel for Hospira Ltd and has acted as a consultant for Bristol-Myers Squibb. C.L. declares participation on advisory panels of Merck, Gilead and Teva within the last year. 


\section{References}

1 Ludwig $H$, van Belle $S$, Barrett-Lee $P$, Birgegård G, Bokemeyer C, Gascón P, Kosmidis P, Krzakowski M, Nortier J, Olmi P, Schneider M, Schrijvers D: The European Cancer Anaemia Survey (ECAS): a large, multinational, prospective survey defining the prevalence, incidence, and treatment of anaemia in cancer patients. Eur J Cancer 2004;40: 2293-2306.

2 Groopman JE, Itri LM: Chemotherapy-induced anemia in adults: incidence and treatment. J Natl Cancer Inst 1999;91:1616-1634.

3 Cella D, Kallich J, McDermott A, Xu X: The longitudinal relationship of hemoglobin, fatigue and quality of life in anemic cancer patients: results from five randomized clinical trials. Ann Oncol 2004;15:979-986.

4 Lind M, Vernon C, Cruickshank D, Wilkinson P, Littlewood T, Stuart N, Jenkinson C, Grey-Amante P, Doll H, Wild D: The level of haemoglobin in anaemic cancer patients correlates positively with quality of life. Br J Cancer 2002;86:1243-1249.

5 Caro JJ, Salas M, Ward A, Goss G: Anemia as an independent prognostic factor for survival in patients with cancer: a systemic, quantitative review. Cancer 2001;91:2214-2221.

6 Aapro MS, Link H: September 2007 update on EORTC guidelines and anemia management with erythropoiesis-stimulating agents. Oncologist 2008;13(suppl 3):33-36.

7 Rizzo JD, Brouwers M, Hurley P, Seidenfeld J, Arcasoy MO, Spivak JL, Bennett CL, Bohlius J, Evanchuk D, Goode MJ, Jakubowski AA, Regan DH, Somerfield MR: American Society of Clinical Oncology/American Society of Hematology clinical practice guideline update on the use of epoetin and darbepoetin in adult patients with cancer. J Clin Oncol 2010; 28:4996-5010.

8 European Generic Medicines Association: Biosimilars Handbook, ed 2. Brussels, European Generic Medicines Association, 2011.

9 European Medicines Agency: Guideline on similar biological medicinal products. 2005. http://www.ema.europa.eu/docs/en_GB/ document_library/Scientific_guideline/2009/09/WC500003517.pdf (accessed December 2014).

10 World Health Organization: Guidelines on evaluation of similar biotherapeutic products (SBPs). 2009. http://www.who.int/biologicals/ areas/biological_therapeutics/BIOTHERAPEUTICS_FOR_WEB_22APRIL2010.pdf (accessed December 2014).

11 Macdougall IC: Biosimilar epoetins. Nephrol Dial Transplant 2009;24:1698-1699.

12 Aapro M, Cornes P, Sun D, Abraham I: Comparative cost efficiency across the European G5 countries of originators and a biosimilar erythropoiesis-stimulating agent to manage chemotherapy-induced anemia in patients with cancer. Ther Adv Med Oncol 2012;4:95105.

Biosimilar Epoetin Zeta: 6 Years'

Experience in Haematology and Oncology
13 Brinks V, Hawe A, Basmeleh AH, JoachinRodriguez L, Haselberg R, Somsen GW, Jiskoot W, Schellekens H: Quality of original and biosimilar epoetin products. Pharm Res 2011;28:386-393.

14 Pharmaceutical Research and Manufacturers of America: Biopharmaceutical research and development: the process behind new medicines. 2007. http://www.phrma.org/sites/default/files/pdf/rd_brochure_022307.pdf (accessed September 2015).

15 Schiestl M, Stangler T, Torella C, Cepeljnik T, Toll H, Grau R: Acceptable changes in quality attributes of glycosylated biopharmaceuticals. Nat Biotechnol 2011;29:310-312.

16 European Medicines Agency: Guideline on similar biological medicinal products containing biotechnology-derived proteins as active substance: non-clinical and clinical issues. 2013. http://www.ema.europa.eu/docs/ en_GB/document_library/Scientific_guideline/2013/06/WC500144124.pdf (accessed December 2014).

17 European Medicines Agency: Guideline on non-clinical and clinical development of similar biological medicinal products containing recombinant erythropoietins (revision). 2010. http://www.ema.europa.eu/docs/en_ GB/document_library/Scientific_guideline/2010/04/WC500089474.pdf (accessed December 2014).

18 European Medicines Agency: Guidance on similar medicinal products containing recombinant granulocyte-colony stimulating factor. 2006. http://www.ema.europa.eu/ docs/en_GB/document_library/Scientific guideline/2009/09/WC500003955.pdf (accessed December 2014).

19 European Medicines Agency: Guidance on similar medicinal products containing somatropin. 2006. http://www.ema.europa.eu/ docs/en_GB/document_library/Scientific_ guideline/2009/09/WC500003956.pdf (accessed December 2014).

20 Mellstedt H, Niederwieser D, Ludwig H: The challenge of biosimilars. Ann Oncol 2008;19: 411-419.

21 Kirkov V, Dimitrova V, Siebert-Weigel M, Wolf-Pflugmann M, Koytchev R, Richter W, Bronn A, Arsova S, Kromminga A: Evaluation of the pharmacokinetics of two recombinant human erythropoietin preparations: epoetin zeta and epoetin alfa. 1st communication: a monocentric, open, randomized, single dose, two-period crossover trial in healthy volunteers. Arzneimittelforschung 2008;58:215-219.
22 Kirkov V, Dimitrova V, Siebert-Weigel M, Wolf-Pflugmann M, Koytchev R, Richter W, Bronn A, Arsova S, Kromminga A: Evaluation of the pharmacokinetics of two recombinant human erythropoietin preparations: epoetin zeta and epoetin alfa. 2nd communication: a monocentric, double-blind, randomized, single dose, three-period crossover trial in healthy volunteers. Arzneimittelforschung 2008;58:220-224.

23 Krivoshiev S, Todorov VV, Manitius J, Czekalski S, Scigalla P, Koytchev R, Epoetin Zeta Study Group: Comparison of the therapeutic effects of epoetin zeta and epoetin alfa in the correction of renal anaemia. Curr Med Res Opin 2008;24:1407-1415.

24 Wizemann V, Rutkowski B, Baldamus C, Scigalla P, Koytchev R, Epoetin Zeta Study Group: Comparison of the therapeutic effects of epoetin zeta to epoetin alfa in the maintenance phase of renal anaemia treatment. Curr Med Res Opin 2008;24:625-637.

25 Krivoshiev S, Wizemann V, Czekalski S, Schiller A, Pljesa S, Wolf-Pflugmann M, Siebert-Weigel M, Koytchev R, Bronn A, Epoetin Zeta Study Group: Therapeutic equivalence of epoetin zeta and alfa, administered subcutaneously, for maintenance treatment of renal anemia. Adv Ther 2010;27:105-117.

26 Baldamus C, Krivoshiev S, Wolf-Pflugmann M, Siebert-Weigel M, Koytchev R, Bronn A: Long-term safety and tolerability of epoetin zeta, administered intravenously, for maintenance treatment of renal anemia. Adv Ther 2008;25:1215-1228.

27 Tzekova V, Mihaylov G, Elezovic I, Koytchev $\mathrm{R}$ : Therapeutic effects of epoetin zeta in the treatment of chemotherapy-induced anaemia. Curr Med Res Opin 2009;25:1689-1697.

28 Dammacco F, Castoldi G, Rödjer S: Efficacy of epoetin alfa in the treatment of anaemia of multiple myeloma. Br J Haematol 2001;113: 172-179.

29 Michallet M, Luporsi E, Soubeyran P, Amar NA, Boulanger V, Carreiro M, Dourthe LM, Labourey JL, Lepille D, Maloisel F, Mouysset JL, Nahon S, Narciso B, Nouyrigat P, Radji R, Sakek N, Albrand H, ORHEO study group: Biosimilars in the management of anaemia secondary to chemotherapy in haematology and oncology: results of the ORHEO observational study. BMC Cancer 2014;14:503.

30 ClinicalTrials.gov: Biosimilar Retacrit ${ }^{\mathrm{TM}}$ (epoetin zeta) in the treatment of chemotherapy-induced symptomatic anaemia in haematology and oncology. 2014. www.clinicaltrials.gov/ct2/show/NCT01626547?term=ery thropoetin+zeta\&rank=2 (accessed December 2014). 
31 Michallet M, Goldet K, Sobh M, Morisset S, Chelghoum Y, Thomas X, Barraco F, Ducastelle $\mathrm{S}$, Labussière $\mathrm{H}$, Renzullo $\mathrm{C}$, Paillet $\mathrm{C}$, Pivot C, Straaten PB, Denis A, Termoz A, Detrait M, Nicolini FE, Jaisson-Hot I: Prospective study of erythropoietin use on quality of life and cost effectiveness in acute myeloid leukemia and allogeneic hematopoietic stem cell transplantation patients. Cancer 2013; 119:107-114.

32 Niederwieser D, Schmitz S: Biosimilar agents in oncology/haematology: from approval to practice. Eur J Haematol 2011;86:277-288.
33 Minghetti P, Rocco P, Del Vecchio L, Locatelli F: Biosimilars and regulatory authorities. Nephron Clin Pract 2011;117:c1-c7.

34 Covic A, Cannata-Andia J, Cancarini G, Coppo R, Frazão JM, Goldsmith D, Ronco P, Spasovski GB, Stenvinkel P, Utas C, Wiecek A, Zoccali C, London G: Biosimilars and biopharmaceuticals: what the nephrologists need to know - a position paper by the ERA-EDTA Council. Nephrol Dial Transplant 2008;23: 3731-3737.
35 Aapro MS, Bohlius J, Cameron DA, Dal Lago L, Donnelly JP, Kearney N, Lyman GH, Pettengell R, Tjan-Heijnen VC, Walewski J, Weber DC, Zielinski C, European Organisation for Research and Treatment of Cancer: 2010 update of EORTC guidelines for the use of granulocyte-colony stimulating factor to reduce the incidence of chemotherapy-induced febrile neutropenia in adult patients with lymphoproliferative disorders and solid tumours. Eur J Cancer 2011;47:8-32.

36 Ebbers HC, Muenzberg M, Schellekens H: The safety of switching between therapeutic proteins. Expert Opin Biol Ther 2012;12: 1473-1485 